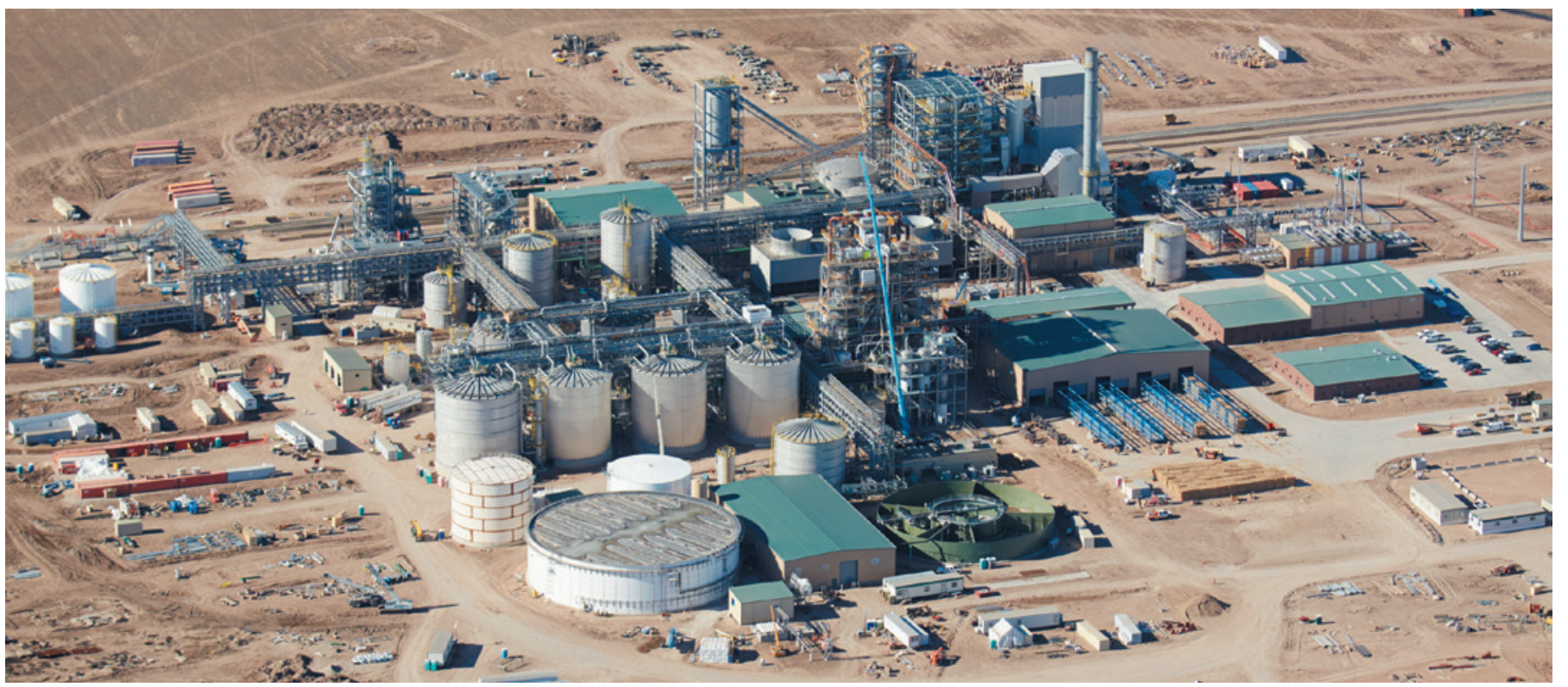

The Abengoa cellulosic ethanol plant near Hugoton, Kansas, will start production this year.

ENERGY

\title{
Cellulosic ethanol fights for life
}

\section{Pioneering biofuel producers hope that US government largesse will ease their way into a tough market.}

\section{BY MARK PEPLOW}

$\mathrm{O}$ $\mathrm{n}$ the flat plains of Kansas, a stack of gleaming steel towers and pipes stretches 16 storeys into the sky. More than 1,000 construction workers toiled to complete the ethanol plant near the town of Hugoton, and its owners expect it to join a fermented-fuel revolution.

But unlike most ethanol factories, in which yeast feeds on sugars in foodstuffs such as maize (corn) kernels, the Hugoton facility will make use of what has been, until now, agricultural waste: cellulose. Thousands of tonnes of corn stover - the leaves, stalks and husks left over after the maize harvest - are already waiting, stacked in square bales, at the 1.6-square-kilometre site. By June, the plant will begin processing the stover into ethanol, which will be blended with petrol and end up in vehicle fuel tanks.

The plant, which is owned by multinational company Abengoa of Seville, Spain, is one of three US facilities that should start commercial production of cellulosic ethanol in the next few months (the others are both in Iowa, one run by POET-DSM Advanced Biofuels and the other by DuPont). The industry has long promised that this second-generation biofuel will cut greenhouse-gas emissions, reduce US reliance on imported oil and boost rural economies. Yet just as the fuel is on the cusp of making it big, market forces and government policies could choke its progress. "This is going to be a very critical year," says Zia Haq, a chemical engineer and senior analyst at the US Department of Energy, which has helped to fund the plants. The challenges have already pushed some researchers and companies towards an alternative approach that converts cellulose into hydrocarbon fuels using chemical rather than biological processes.

With more than 200 operating plants, the corn-ethanol industry is well established in the United States. Its dramatic growth has been driven by tax credits and the Renewable Fuel Standard (RFS), created by law in 2005 and extended in 2007. Administered by the US Environmental Protection Agency (EPA), the standard mandates annual increases in the volumes of various renewable fuels included in the country's fuel supply. In its early years, the law emphasized the production of corn ethanol, considered ripe for early commercialization.

Yet corn ethanol comes with problems. It offers only modest savings in greenhouse-gas emissions compared to petrol (see Nature 499, 13-14; 2013). Production is vulnerable to poor harvests and can contribute to increased food prices because the maize must be grown on land that would otherwise be used for food. Tapping the storehouse of biomass left after the harvest is much less controversial. Ethanol made from corn stover produces at least $60 \%$ less greenhouse-gas emissions than petrol, and making it does not require any extra farmland.

Brewing such cellulosic ethanol, however, is hard. Producers must dismember large, indigestible molecules such as cellulose and hemicellulose to yield fermentable sugars. The process requires the biomass to be ground up and pretreated with acids. A cocktail of enzymes must then be applied to chop up the tough biological polymers inside - all before the yeast is added to the resulting sugars. Hence the scale of Abengoa's processing facility, much larger and more expensive than any corn-ethanol plant. According to the RFS, commercial production of cellulosic ethanol was meant to start around 2010, but that did not happen. With patchy investment backing, many companies have fallen by the wayside.

\section{BLEND WALL}

Part of the problem is that the ethanol market is already saturated. In 2012, the industry produced more than 50 billion litres of corn ethanol, comprising $10 \%$ of US transportation fuel - enough to completely satisfy demand for the E10 petrol blend that most vehicles now burn (see 'Hitting the wall'). This 'blend wall' puts an upper limit on the amount of ethanol 
ส that the market can absorb. And it is closing in: demand for petrol has actually fallen, and 这 there is growing interest in alternatives such as $\underset{\infty}{m}$ battery-powered cars. Cellulosic ethanol may now be arriving, but its timing is terrible. "We don't have room for any more ethanol," says Wallace Tyner, an agricultural economist at Purdue University in West Lafayette, Indiana.

Corn ethanol is now slightly cheaper than petrol, but cellulosic ethanol is more expensive than both. A cellulosic-ethanol plant's capital costs are roughly twice those of a cornethanol plant, says Tyner, and enzymes raise operational costs further. Unable to undercut its rivals, cellulosic ethanol will be heavily dependent on the RFS to clear its path to the pumps. Yet its delayed arrival has prompted the EPA to reduce the amount of cellulosic ethanol that refiners are required to blend into their petrol.

The RFS plan for this year originally called for 6.6 billion litres of cellulosic ethanol. But in November, the EPA proposed that the mandate should be reduced to 64 million litres, a mere trickle in comparison. A final ruling is expected in March or April. Groups working on renewable fuel, who say that producers will easily make more than 64 million litres once they get going, have cried out. "We think the EPA underestimated the capacity of the industry," says Christopher Standlee, executive vicepresident of global affairs for Abengoa. The expensive excess ethanol might have to be sold at a loss on the open market, potentially crippling the fledgling industry.

\section{CAPACITY PROBLEM}

Cellulosic-ethanol producers have several options to increase their market. First, they could break through the blend wall. All US vehicles produced in the past decade can run on a $15 \%$ ethanol-petrol blend - but consumers and distributors are mostly unconvinced, perhaps spooked by car-industry studies claiming that the fuel damages engines.

Another way over the wall might be exports to the European Union, which aims to make $10 \%$ of its transportation fuel renewable by 2020. And cellulosic ethanol could get cheaper with more efficient stover harvesting, beefier enzymes and cheaper pretreatments. The industry has already cut costs from as much as US\$9 per gallon ( $\$ 34$ per litre) five or six years ago to close to $\$ 2$ today, says Thomas Foust, director of the National Bioenergy Center, part of the National Renewable Energy Laboratory in Golden, Colorado.

But Tyner says that this approach can be squeezed only so far. He and others see more promise in a different approach to breaking up cellulose - a brute-force combination of temperature, pressure and chemistry. These thermochemical methods can produce either a crude bio-oil or a stream of carbon monoxide and hydrogen known as syngas. After further treatment and refining with the help

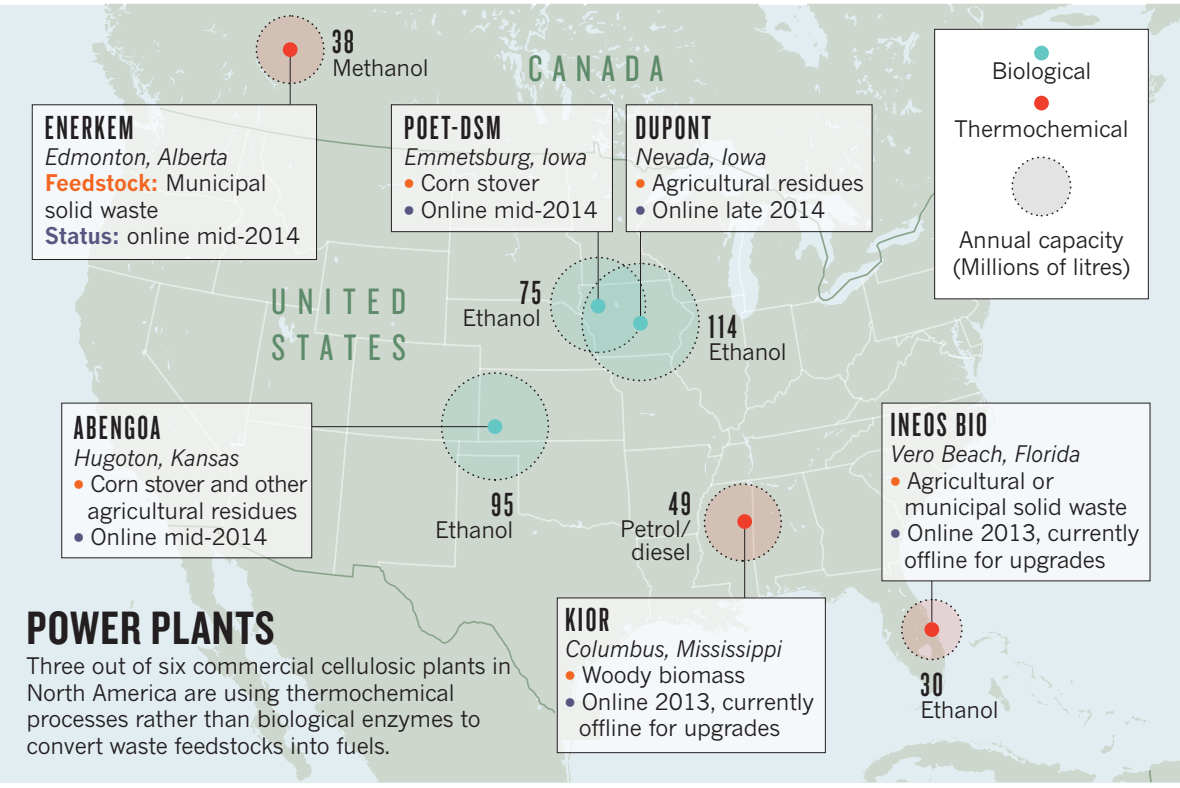

of chemical catalysts, both can be turned into hydrocarbons such as petrol, diesel and jet fuel. Crucially, these 'drop-in' fuels, named because they can replace normal fuels with no adjustments to engines, have no blend wall to vault.

Thermochemical routes can also use lowerquality feedstocks, tearing through anything from wood chips to municipal solid waste. Enerkem, a company in Montreal, Canada, is starting its first commercial-scale plant to turn solid waste into syngas, in Edmonton. By April or May, it will be able to transform the syngas into methanol. Next year, it plans to convert the methanol into ethanol, and it says that will be cheaper than corn ethanol.

This is mostly because the feedstock is cheap. US landfill fees for solid waste are about $\$ 44$ per tonne, not including transportation, so municipalities are keen to get companies such as Enerkem to take the waste off their hands, says Marie-Hélène Labrie, the company's vicepresident for government affairs and communications. "Generally, we're being paid to take the feedstock."

\section{HITTING THE WALL}

There is already enough corn ethanol to satisfy US demand for a widely used $10 \%$ ethanol-petrol blend, in part because petrol consumption is declining.

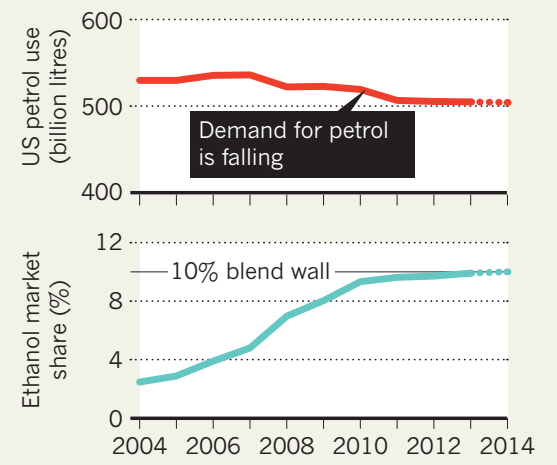

Producing syngas also gives the company a lot of flexibility. If there are changes to policy mandates or the market, the system could be switched to making hydrocarbon fuels or higher-value chemical products. Enerkem plans to build similar plants in Mississippi and Quebec next year, and it is partnering with Waste Management in Houston, Texas - the biggest US landfill operator — to take its waste.

Research funding, too, is shifting to thermochemical methods, says Haq. "That doesn't mean we're abandoning cellulosic ethanol," he says. "But certainly, going forward, we're looking more seriously at hydrocarbon pathways."

Last year, an energy-department project to supply the US Navy with advanced biofuels provided funding for four facilities that will all use thermochemical methods to make drop-in fuels. Thermochemical processes are also key to the first two commercial cellulosic plants in the United States, which opened last year: KiOR in Columbus, Mississippi, and INEOS Bio near Vero Beach, Florida (see 'Power plants'). (Both plants are currently idle, pending upgrades.) Haq thinks that longerlived catalysts will further reduce the costs of thermochemically produced cellulosic hydrocarbons in coming years.

But Standlee says that biology can still compete, by tackling ever-cheaper feedstocks. His company is betting that a new generation of enzymes can turn municipal waste into ethanol, and last July it opened a demonstration plant near Salamanca, Spain, to do just that. Abengoa hopes that this technology will eventually allow it to expand its US operations beyond the 'corn belt'.

Standlee says that, as long as the cellulosic industry is given time to mature - just as corn ethanol was - it can get back on the trajectory set out by the RFS. "If," he adds, "the EPA sticks with the programme." 